\title{
Paulus Handbuch
}

\author{
Hrsg. v. Friedrich W. Horn
}

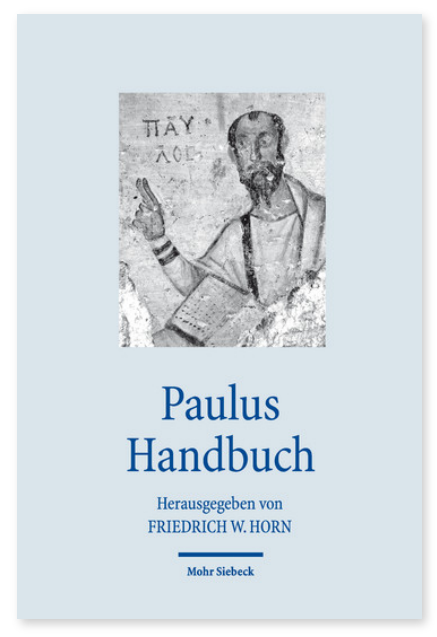

2013. XVI, 653 Seiten. HdTh

SBN 978-3-16-152665-7

DOI 10.1628/978-3-16-152665-7

eBook PDF $119,00 €$

ISBN 978-3-16-150082-4

fadengeheftete Broschur 49,00€

ISBN 978-3-16-150083-1

Leinen $119,00 €$
Paulus ist, um ein berühmtes Votum Rudolf Bultmanns aufzunehmen, zum Begründer einer christlichen Theologie geworden. In diesem Buch stehen die Person des Paulus und sein Werk im Mittelpunkt. Wir blicken heute auf eine rege, mit Ferdinand Christian Baur in der Mitte des 19. Jahrhunderts einsetzende Forschungsgeschichte zurück und befinden uns gegenwärtig in einer recht offenen und von höchst divergenten Ansätzen bestimmten Forschungssituation. Die großen Epochen des vergangenen Jahrhunderts - die Religionsgeschichtliche Schule, die Kerygmatheologie Rudolf Bultmanns und seiner Schüler und die 'New Perspective on Paul' - sind keineswegs überholt. Ihren Fragen und Ergebnissen gegenüber ist die Forschung bleibend verpflichtet. Zum Ansatz gegenwärtiger Paulus-Exegese gehört seit einigen Jahrzehnten, dass in einem Dreischritt das Leben des Apostels, seine Briefe und seine Theologie gleichwertig bedacht werden und dass sich aus der Zusammenschau dieser Aspekte erst ein Gesamtbild ergibt. Die jüngere Forschung hat hinsichtlich des Lebens des Apostels auf den bleibenden jüdischen Untergrund aufmerksam gemacht, der vor allem im Schriftgebrauch Ausdruck findet. Paulus entfaltet sein theologisches Denken im Gespräch und in der Auseinandersetzung mit seiner Tradition, mit seinen Mitarbeitern, seinen Gemeinden und den ihn bedrängenden Gegnern, aber auch in möglichst präziser Wahrnehmung der Religiosität und Kultur der Städte seiner Gemeinden. Es ist die konstruktive Aufgabe der Exegese, auf der Grundlage aller vermutlich authentischen Briefe und unter Berücksichtigung des Lebens des Apostels eine Theologie des Paulus zu entwerfen. Gegenwärtig scheint hierfür der Gedanke einer partizipatorischen Christologie leitend zu sein. Das Paulus Handbuch stellt Leben, Briefe und Theologie des Paulus dar und rahmt diesen Schwerpunkt mit der Forschungsgeschichte und mit einem Ausblick auf Wirkung und Rezeption des Apostels. Mehr als vierzig Autorinnen und Autoren beschreiben den Weg des Pharisäers Paulus zum Heidenapostel, analysieren seine Briefe und rekonstruieren das Werden seiner christlichen Theologie. Eine durchgehende Lektüre des Handbuchs wird die Leserschaft mitnehmen in eine breite, vielleicht für manche in ihren althistorischen, epistolographischen, kultur- und sozialgeschichtlichen Fragestellungen neue und ungewohnte Forschungslandschaft.

Friedrich Wilhelm Horn Geboren 1953; 1972-78 Studium der Ev. Theologie in Wuppertal und Göttingen; 1982 Promotion; 1990 Habilitation; seit 1996 Professor für Neues Testament an der Johannes Gutenberg-Universität Mainz.

Jetzt bestellen:

https://mohrsiebeck.com/buch/paulus-handbuch-9783161526657?no_cache=1

order@mohrsiebeck.com

Telefon: $+49(0) 7071-923-17$

Telefax: $+49(0) 7071-51104$ 